\title{
Cranking Up Cornerstone: Lessons Learned from Implementing a Pilot with First-Year Engineering Students
}

\section{Dr. Susan F. Freeman, Northeastern University}

Susan Freeman, is a member of Northeastern University's Gateway Team, a group of teaching faculty expressly devoted to the first-year Engineering Program at Northeastern University. The focus of this team is on providing a consistent, comprehensive, and constructive educational experience that endorses the student-centered, professional and practice-oriented mission of Northeastern University.

\section{Dr. Courtney Pfluger, Northeastern University}

Dr. Courtney Pfluger received her Doctoral degree in Chemical Engineering from Northeastern University in 2011. In the fall of 2011, she took a position as an Assistant Teaching Professor at Northeastern University in the College of Engineering as a part of the First Year Engineering Faculty with a focus on chemical engineering. She teaches the first year courses where are Engineering Design and Engineering Problem Solving. She also teaches senior Chemical Engineering Process Controls. She runs a faculty led international summer program to Sao Paulo, Brazil which focuses on Alternative Energy Technologies and Brazilian Culture.

\section{Dr. Richard Whalen, Northeastern University}

Dr. Richard Whalen is a Teaching Professor at Northeastern University in Boston, MA and a core member of the Engineering Gateway Team. The focus of this team is on providing a reliable, wide-ranging, and constructive educational experience that endorses the student-centered and professionally-oriented mission of the University. He also teaches specialty courses in the Department of Mechanical and Industrial Engineering at Northeastern and has published and presented papers on approaches and techniques in engineering education. He has won multiple Outstanding Teaching Awards at Northeastern and numerous Best Paper and Best Presentation Awards with fellow Gateway coauthors at ASEE.

\section{Dr. Kathryn Schulte Grahame, Northeastern University}

Dr. Kathryn Schulte Grahame is an Associate Teaching Professor at Northeastern University. As part of her Gateway Faculty appointment she teaches freshman engineering courses as well as undergraduate civil engineering courses.

\section{Dr. Joshua L. Hertz, Northeastern University \\ Dr. Chirag Variawa, Northeastern University}

Dr. Chirag Variawa teaches first-year engineering design at Northeastern University. He received his Doctorate in Industrial Engineering, focusing on Language Inclusivity in Engineering Education from the University of Toronto. His undergraduate degree is from the same institution, from the Dept. of Materials Science and Engineering.

\section{Mrs. Jennifer Ocif Love, Northeastern University}

Jennifer Love is a member of Northeastern University's Gateway Team, a selected group of faculty devoted to the First-Year Engineering Program. The focus of this team is to provide a consistent, comprehensive, and constructive educational experience in engineering that endorses the student-centered and professionally-oriented mission of Northeastern University.

Dr. Mark L. Sivak, Northeastern University

Dr. Bala Maheswaran, Northeastern University

Bala Maheswaran, PhD Northeastern University 367 Snell Engineering Center Boston, MA 02115 


\title{
Cranking Up Cornerstone: Lessons Learned from Implementing a Pilot with First-Year Engineering Students
}

\begin{abstract}
$\underline{\text { Abstract }}$
This paper presents evidence-based practice in required first-year engineering curriculum at Northeastern University. It will outline the motivation to redesign the curriculum, and include review of engineering education practice that inspired and directed the change, along with evidence and assessment of the effectiveness of the new approach. In 2012, after a comprehensive curriculum review by a faculty committee at Northeastern University, the firstyear engineering program decided to adopt the "cornerstone to capstone" curriculum design. The overarching goal of the cornerstone was the integration of design, programming, graphical communication, and engineering analysis through real world, hands-on design projects previously taught in two separate courses. This goal directly supports the interdisciplinary, student-centered approach recommended by the National Academy of Engineering's Educating the Engineer of 2020 report. $^{13}$
\end{abstract}

Additional motivation for the cornerstone approach came from three areas; student feedback, the changing profile of first year students, and increased access to affordable technologies such as programmable microcontroller kits and 3D printing. Today's students are entering the university with more advanced placement credit and an increased level of experience with hands-on projects and technologies, such as electronics. This cohort of students are looking for more depth in exploring engineering and a sense of real world problems along with taking courses at an accelerated pace.

First pilots of the cornerstone course included a 14-week, 400-minutes per week course. Several measures were reviewed to evaluate success of the cornerstone. In comparing course content artifacts from the previous courses to similar ones from cornerstone, the cornerstone students of similar entrance skills did as well as the previous students on tests, projects, quizzes and presentations. Cornerstone students also reported similar positive outcomes for learning in the new course compared to students in the traditional courses, and even reported how they couldn't imagine the courses not integrated.

This paper will report on the motivations and lessons learned at Northeastern University in implementing a cornerstone approach. It will present evidence-based practice in required firstyear engineering curriculum at Northeastern University and will outline the motivation to redesign the curriculum. It will include review of engineering education practice that inspired and directed the change, along with evidence and assessment of the effectiveness of the new approach. 


\section{Introduction}

A decision to change curriculum can be motivated in a number of ways. The least favorite is from student complaints but this was not the motivation at Northeastern University, the students had commented occasionally on wishing they could "build" more. In 2012, after a comprehensive curriculum review by a faculty committee representing mathematics, physics, chemistry and all engineering departments at Northeastern, the first-year engineering program decided to adopt the "cornerstone to capstone" curriculum design. The committee considered the research on how people learn, consulted published engineering education research on cornerstone programs at other universities, and acknowledged students' strengths and weaknesses, including their increasing numbers of applying AP credit toward college. Further review led to incorporating the integration of hands-on, project-based design projects with computer programming and the "cornerstone to capstone" approach.

\section{$\underline{\text { Review and Literature Review }}$}

As a result of the ongoing dialogue to improve engineering education and the proven initiatives supported by the National Science Foundation and other funding agencies, cornerstone courses in the first year of engineering are growing with popularity and many universities have been introducing them into their curriculum. ${ }^{1-10,14-18}$ These courses may be taught by a dedicated group of faculty with engineering experience in industry, who may be more design-oriented (as opposed to research-oriented), and who may have demonstrated exemplary teaching abilities that engage first-year engineering students. ${ }^{11,12}$ Additional motivations for this approach include better career preparation for engineering students and improved engineering education in general.

The University of Virginia found that cornerstone courses had better course ratings by students than traditional sections and that graduation retention rates were higher with students who had taken the cornerstone courses compared to the traditional sections. ${ }^{5}$ In another study, also at the University of Virginia, they studied whether hybrid instructional design and hands-on design activities in a cornerstone course helped students learn the engineering design process. ${ }^{2}$ In this study, Donahue used previously validated instruments to measure and show that students robustly learned the engineering design process. Embry-Riddle Aeronautical University and Ohio State University studied whether some degree of instructional scaffolding helped students to engage in more design-oriented activities in a cornerstone course and found that first-year engineering students did exhibit more sophisticated designer-like behavior in a project-based learning setting. ${ }^{1}$ McMaster University surveyed 420 first-year engineering students in a cornerstone course and found that the cornerstone course was successful at implementing a hands-on problem of practice that offered a balance between fully open-ended and completely prescribed design criteria. ${ }^{3}$ In this study, Doyle stated that "the objective of the cornerstone is to instill in first-year engineers enjoyment from learning, motivation to continue learning, and genuine intellectual curiosity about engineering in the world around them." The University of 
Toronto applied a hybrid framework of behaviorist and constructivist learning models to design a cornerstone course. ${ }^{14}$ The learning models were applied using the Elaboration Theory to allow a gradual transition from content-based to project-based design education. Students' feedback indicated great enthusiasm for the course despite the heavy workload. Their course evaluations confirmed that they met the expected qualifications of design engineers.

Dym, Agogino, Eris, Frey and Liefer at Harvey Mudd College, University of California Berkley, Stanford University and Massachusetts Institute of Technology conducted their own literature review of project-based learning and cornerstone courses to determine whether divergent and convergent thinking in the engineering design process could be used iteratively to develop better pedagogical approaches to engineering design and analysis. ${ }^{18}$ They concluded that project-based learning increases retention of engineering students and that there is a clear need to increase the number of faculty who can teach engineering design and to create facilities and design studios to support project-based design courses.

California Polytechnic State University used a constructivist design model to develop a projectbased cornerstone course and found that the pilot course was an empowering experience for the students, although there was no difference between males and females. ${ }^{6}$ Researchers concluded that collaboration and life-long learning skills can help improve student retention rates and that the constructivist course model can substantially reduce faculty effort in teaching such a projectintensive course. "Cornerstone courses involve creating an interesting problem, possibly in an unfamiliar field, working and managing student teams, and assessing individual and team contributions while accommodating the skill level of incoming freshmen." and level of effort in teaching in this way should not be under-estimated.

Northwestern University described an interdisciplinary, project-based cornerstone course where students acquire skills in communication, design and teamwork as they learn that engineering is an iterative and creative problem-solving process. ${ }^{15}$ The Royal Institute of Technology in Sweden demonstrated how cornerstone and capstone courses can be integrated by the same department. ${ }^{16}$ Grimheden stated that "the purpose of cornerstone projects is to introduce the students to their future professional role as design engineers" and "the primary aim is to teach design methodology and to enable the students to practice and improve teamwork skills". ${ }^{16}$ So the "cornerstone to capstone" model can work for some institutions.

In addition, engineering learning spaces are also being built to support undergraduate engineering education, sometimes specifically for first year engineering students. At the University of South Australia, a large new learning space called "Experience 1 Studio" opened in 2009 to help students adapt to university life, develop peer networks, benefit from collaborative learning and engage with their studies. ${ }^{19}$ In fact, this learning space was shown to help students transition to college, especially women and minorities. At Yale University, the new Center for Engineering Innovation and Design was opened in 2009 to support the addition of 2 new engineering cornerstone courses. ${ }^{20}$ The new center is 8,500 square feet and was designed to provide space to students and faculty for instruction, meetings, machine shop manufacturing and 
fabrication, plus 3D printing. After only 18 months of operation, Yale University was able to develop assessments in each engineering course to measure Student Outcomes per ABET criteria.

At Michigan State University, a more comprehensive approach to first-year engineering was established in 2008 which integrated cornerstone courses, an engineering living-learning residence hall, computer labs and a project work space. 9, 21, 22 Compared to Northeastern University, Michigan State's enrollment is comparable in size (about 700+ first-year engineering students each fall). Michigan State researchers discovered that engineering students living in the special residence hall attended more evening seminars and more tutoring than students who did not live there. In addition, female students were more likely to return to the engineering residence hall than males the following year.

In addition, in 2008, an electrical engineering PhD student at Michigan State University conducted a dissertation study entitled "Measurement of Student Attitudes in First Year Engineering - A Mixed Methods Approach" in which 398 out of 772 students were tracked, interviewed and surveyed. ${ }^{17}$ Results indicated that students joined the program with strong positive attitudes toward engineering and were influenced by their parents and teachers, childhood experiences and high school activities. The cornerstone students enjoyed the teamwork and problem solving aspects of engineering but did report some negative experiences regarding the workload and expected level of teamwork in the cornerstone course compared to students enrolled in traditional sections. At Michigan State, cornerstone courses, living-learning communities and engineering learning centers together have been effective in improving the quality of undergraduate engineering education especially in the first year.

This extensive work in demonstrating the educational value of the cornerstone approach in firstyear engineering courses started the ball rolling improving our first year courses. This was combined with the University committee's suggestions that a course redesign would have real world, hands-on, integrated project focus, with recommended themes to help students explore majors and accelerate their engineering careers, along with an awareness of a changing student profiles. This combination of factors supplied the motivation for the curriculum changes that are continuing to evolve.

\section{$\underline{\text { Pilot Cornerstone - Motivation for a New Approach }}$}

The first-year curriculum at Northeastern University has undergone a number of iterations over the last several years and continues to evolve as it moves towards full implementation of the cornerstone model. ${ }^{23-32}$ The first-year is common for all engineering majors and there are two general engineering courses offered each semester of about 25 separate sections with approximately 30 students each. The first course in the series focuses on learning the principles of engineering and design; this is accomplished through active learning in areas such as problem definition, conceptual design, preliminary and detailed design, design communication and implementation, along with report writing and presentations in relation to projects that students 
produce in teams. There is a strong emphasis on applying technical knowledge, developing problem-solving and decision-making skills, and using computer-aided design (CAD) to communicate graphically. The second course concentrates on developing algorithmic thinking skills and solutions to real-life problems using software tools such as Mathworks' MATLAB and the $\mathrm{C}++$ programming language. Problems used in both courses are deliberately chosen to apply engineering and cover topics from all majors. The course also has a hands-on component using low-cost programmable microcontrollers and electronic kits and components that students use to solve real-world engineering design problems.

The main reason a common first-year curriculum was instituted at Northeastern is because of the many students who enter undecided (approximately 40\%). Accommodations are needed for these students so that they have an opportunity to explore all of the 7 engineering majors without a penalty. In addition to a large cohort of undecided students, the university is seeing an increased number of students coming in with college credit, either AP or other. In 2014, over $50 \%$ of entering students had some AP credit in Calculus, $20 \%$ had Chemistry credit, $35 \%$ have College Writing credit and 35\% have Physics credit, all required first-year courses in the curriculum. These students face a limited course selection to complete their academic schedules in these early semesters since it is difficult to find courses that they can take in the first year that do not have prerequisites. This created the need to revise the curriculum to offer students the opportunity to accelerate their exploration of an engineering major. In order to accomplish this, students take both of the general first-year engineering courses in the fall semester. This in turn frees up one course in their spring semester to explore introductory courses in their major that would not usually be seen until the sophomore year. By Fall 2014, there were over 150 of our students enrolled in the two courses simultaneously in the Fall semester.

The pilot first-year cornerstone course was implemented in Fall 2014 with 2 sections, a total of 66 students were enrolled. The course incorporates all of the elements of both the first and second semester courses combined into one 8 credit hour course with the intention of having major-specific themes (or more tailored to a limited number of majors) to allow for further exploration of a major by the students. The 8 credit course was limited to honors students only because; first, they were more likely to have the need to take both the first and second semester first-year courses in the first semester due to advanced placement credits and second, they were more likely to be able to handle the pace and pressure of taking both of the courses integrated instead of concurrently. In 2015, 4 sections (3 honors and 1 non-honors) of Cornerstone were offered to accommodate more than 130 students.

In designing the new cornerstone, one of the key elements was that all of the original course material from both of the original courses remained. The cornerstone courses were carefully designed to set up our first-year students to be successful in their 2 nd year of engineering regardless of major selection. Therefore the new course includes specific themes centered on a number of design-and-build projects with the core outcomes of:

- Applying the design process.

- Design and construct to design specifications.

- Engineer a solution to a real problem. 
- Graphical Communication and 3D printing.

- Professional skills: oral and written skill practice, presenting design solutions.

- Computational programming skills - $\mathrm{C}++$, Matlab, using programmable microcontrollers.

- Focus on sensing and input/output.

- Numerical analysis and calibration of sensors.

Also in order to free up class time for project work, many of the course elements were flipped. The flipped classroom model allows more time for hands on activities, team project work, and in-class feedback from the professor. Additional advantages to the cornerstone model are that the students are able to design projects with a systems approach, and to simulate real projects with complex solutions. Core course concepts such as applications of programming, graphics and the design process are integrated naturally and are not forced. This gives immediate confirmation that the topic is relevant as they have to apply it in order to solve their problem. Finally, students can explore and research engineering principles due to their interest and the project requirements which leads to further fulfillment of effort.

Figure 1 below shows a conceptual framework for the cornerstone experience at Northeastern University. This model helps visualize how the goal of this program is to weave together three theme areas into an integrated design experience. From left to right, we see that the learning objectives include students being able to evaluate and interpret design, conceptualize and prototype them, as well as communicate these experiences in diverse ways, in addition to others. This visualization of cornerstone allows the program instructors to organize learning objectives together, which can help in planning, teaching, and assessment purposes.

Project-based cornerstone has, as one of its challenges, the ability to have incongruent learning of course content due to the nature of problem solving. By highlighting that engineering problem solving brings together groups of competencies in a networked fashion rather than in a linear fashion, we can help increase the quality of instruction for all students by showing them that this incongruence is acceptable. Specifically, the emphasis here is that cornerstone is a lens by which engineering learning can come together to develop practical applications to solving problems. By representing cornerstone as a ring that brings together three theme areas, the conceptual framework focuses on the notion that it blends together seemingly separate aspects into a useful weave of skills in a problem solving context. 


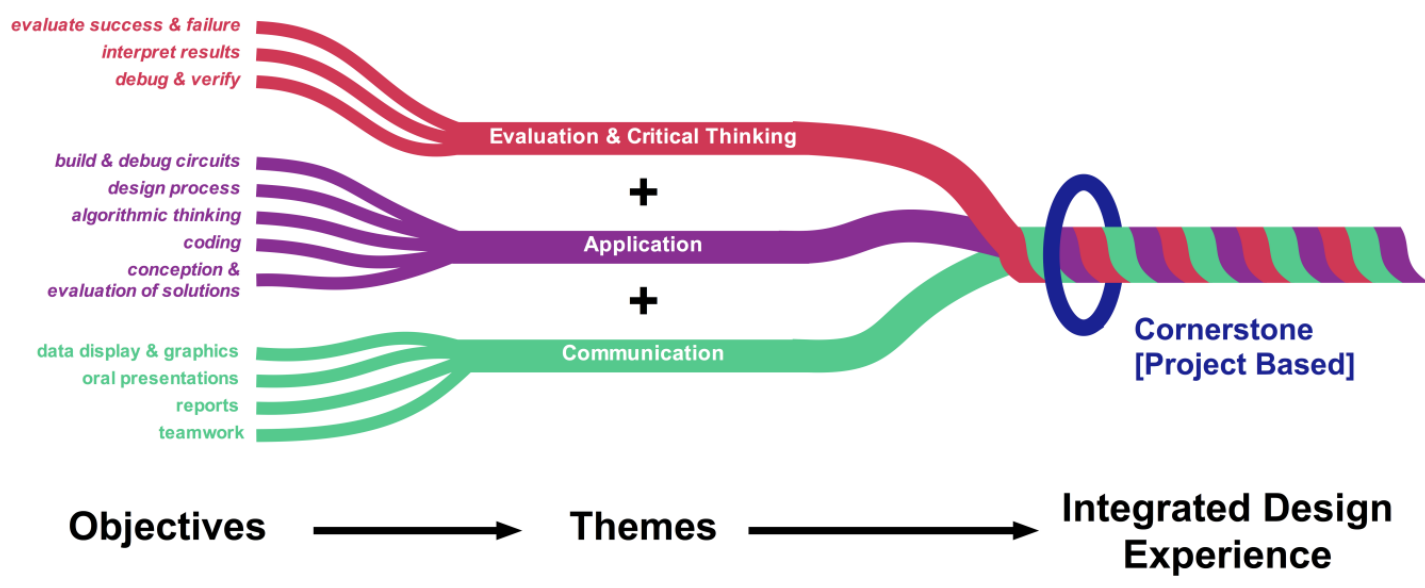

Figure 1 - Conceptual Model of Cornerstone Course

\section{$\underline{\text { Pilot Cornerstone }- \text { Structure and Content }}$}

First pilots of the cornerstone course included a 14-week, 400 minutes per week, 8 credit hour course that combined and integrated all of the content, hands-on projects, flipped classroom and themes as the first Cornerstone of Engineering course. Logistical concerns led the team to consider a second pilot study the following year to include both a 14-week course, 8-credit versions and a 28-week, 2 separate 4 credit versions over Fall and Spring. This paper will focus on results from the 8 credit course, with discussion of the other at the end of the paper.

In 2014, 2 sections of Cornerstone were piloted, with two different themes. The students were selected from the honors cohort, all students that were eligible had AP Chemistry credit, as Chemistry is required in the Fall. They selected which theme they were most interested in, and if it fit their schedule, they were placed in a section. The Robotics theme had 35 students, the Sustainability theme had 31. The two instructors worked together during the summer to develop consistent approaches, schedules, and commensurate projects. The result was that each course had several milestone projects, done in teams, with a team-built, working project, an accompanying report and team presentation. Individually, each student did similar homework assignments, tests and quizzes in AutoCAD, Solidworks, Excel, Design, and Programming. Many of these were themed, but as both instructors had taught the separate courses in the past, the work and quizzes were similar in rigor and content to those given in previous years.

In the Robotics theme, there were 3 major project milestones. The students had to build a robot starting with a basic breadboard and adding all of the motors and sensors, along with learning to program the board and robot. They were concurrently learning $\mathrm{C}++$, the Design Process, AutoCAD, Solidworks and Data Analysis in order to build a working prototype of a robot. In addition they needed to collect and analyze data to improve the robot performance, calibrate sensors and graphically communicate their designs. Some students also were in robotics servicelearning projects, where they were teaching and designing curriculum for local community 
robotics programs. Their first project milestone was to compete in a Sumo Robot competition where the robot chassis were fundamentally the same design. Their job, therefore, was to focus on the program with the emphasis on good algorithmic design in order to gain a competitive advantage. The second project milestone was to design mechanical additions to the robot, within constraints, to gain a competitive advantage. They also had to write a report on their design and programming for the Sumo Robot projects. The last milestone was the major project which was started at the beginning of the semester and worked on every week, using the design process as they also built the project. The groups chose a robot design problem from a number of different scenarios. Each team built and demonstrated this robot prototype, along with writing a report and a final design presentation. The emphasis was the application of the design process, integrating the programming, the graphical communication, data analysis, and a working autonomous robot, along with any other elements of the course used. Students also individually completed a programming project that analyzed data, using both $\mathrm{C}++$ and Matlab, along with other individual work such as graphics homework, programming labs and Excel assignments.

In the Sustainability theme, there was one semester long design project and three minor design projects given throughout the semester. The object of the semester long design project was to design a sustainable and independent home in Greater Boston by completely eliminating the use of energy and water from outside sources and utilize local and/or sustainably harvested/produced materials. Students used AutoCAD to design their homes which had to be drawn to scale with piping and electrical systems incorporated. The three minor design projects were used to learn and build on the idea of sustainability and sustainable buildings. These projects were hands-on where the students designed, tested, and analyzed data from their designs and were able to use that data to redesign and improve upon their original designs. The first hands-on minor design project was to design and build a solar water heater that provided the warmest water for the longest time compared to others groups in the class. This project allowed students to test and apply their knowledge of heat transfer and solar radiation and mapped to the semester design project by knowing how to use solar radiation to heat the water in their homes versus using electricity. The students had to collect and analyze data using Matlab from their first design, report their findings to the class, and use that data to help them redesign a better solar water heater. They had to write a report on what they learned from the project. The second minor design project was to build a thermostat using Arduino microcontroller boards. They had to make a thermostat using temperature sensors and an LCD screen and write code so the Arduino run thermostat would turn on and off to simulate conserving energy in a home. Lastly, the third minor design project was to design a passive solar box with the goal to maintain the temperature inside the box between $65^{\circ} \mathrm{F}$ and $85^{\circ} \mathrm{F}$ for the longest time possible compared to other groups in the class. This project was to help students understand how heat transfer from the sun can affect a home by specifically maximizing the sun's solar radiation heat to decrease the use of electrical heating systems in a home. The students had to determine which materials and how much should be used as a thermal mass within their passive solar boxes. The students again measured the temperature inside the boxes over 5 days and analyzed the data using Matlab and $\mathrm{C}++$ to determine how to best design their boxes. 


\section{$\underline{\text { Pilot Cornerstone - Outcomes, Assessment and Next Steps }}$}

Several measures were reviewed to evaluate success of the first pilot cornerstones. Similar assessments are planned for the Fall 2015 8-credit 28-week pilot and discussed in the concluding sections. In comparing course content artifacts from the previous courses to similar ones from cornerstone, the cornerstone students of similar entrance skills did as well as the previous students on tests, projects, quizzes and presentations. This was done by comparing the scores and grades on the same major pieces from the same instructors for honors and non-honors students. For the same instructor, the scores were not significantly different on any item and the overall course grades were not significantly different. This is one desired outcome, the students are performing as well on these assessments before and after the change to cornerstone. These represent one type of learning and outcome, below there are results from student reflections that the desired outcome of being able to integrate the course threads and skills as shown in the theoretical framework were also achieved.

Cornerstone students also reported similar positive outcomes for learning in the new course compared to students in the traditional courses, and even reported how they couldn't imagine the courses not integrated. In teaching evaluations, the reported scores for each instructor were slightly lower, but not significantly different than the teaching evaluation scores received on the separate courses. Since this was the first time with the new curriculum, this result is not surprising. Comments were reviewed carefully in order to improve both courses for the next year. One prevalent comment was the desire for more organization on course schedules. Both instructors had laid out a schedule, but found that due to the doubled-up nature of the course, that keeping to this was challenging and keeping the students informed of the many assignments, milestones, project actions and outside work also was formidable. Students also commented on the flipped classroom approach, most liking it, but not liking the online quizzes. These aspects are mostly logistical and somewhat expected. There was definite concern for the large amount of work in the condensed time frame, and this comment has persisted, as seen in other universities. ${ }^{17}$ This is the motivation for the pilot of the cornerstone course over 2 semesters instead of one the one 8 credit version. Since the final cornerstone projects required students to build working prototypes that combined engineering and design concepts from both traditional courses, the integrated cornerstone approach successfully met the main motivations, along with interdisciplinary learning, and additional themes have been developed for the current pilot.

As described above, student reflections on what they learned in the pilot cornerstone sections provides a more complete mapping to the motivation and the desired framework for the course. At the end of the course the students were asked to do a reflection on the course and what they had learned and experienced. All of the students were asked the following 4 questions:

1. Explain how you integrated design and programming in one of your projects in this course.

2. Discuss how the projects in this course connect with real-world engineering problems. 
3. Write a detailed problem statement from one of the engineering problems discussed in question 2 above.

4. Explain how programming is needed in engineering problem solving. List examples from the course.

\title{
Question 1: Explain how you integrated design and programming in one of your projects in this course. Numeric results are shown in Table 1.
}

\begin{abstract}
All 35 of the robotics students mention either the Sumo 2 robot (that incorporates design and programming) or the final robotic design project (autonomous working robot). Each student wrote a paragraph or more with considerable detail on how they accomplished this integration of design and programming. It is not surprising that the integration was seen more on the later projects, because in the early projects and sections of the course, they first needed to learn basic skills before they could be applied and integrated. In the sustainability course, the integration was seen in later projects also.

Comments from question 1 :

"the integration of design and programming was crucial to the success of our robots throughout this course" and at the end of the paragraph "the code and design synthesized together to allow for our robot to work".
\end{abstract}

"This project truly showed us how programming and design could be used in conjunction to create a product that is effective."

"Overall, this project provided the perfect opportunity to use the entire design process including the iteration step as well as programming using Arduino and the breadboards to achieve a common goal."

"This was also done with much greater detail in $C++$ after our revised design was tested (including the calculation of change in temperature between increments), giving a very comprehensive analysis of the functionality of our design."

"This is a great example of the usefulness of using programming in conjunction with design to help analyze a design and improve it."

"The project that most completely integrated design and programming was the passive solar box minor design project. This was especially true of the redesign and second analysis phase of the project, which was partially incorporated into our final $C++$ project. The design process for this project involved researching passive heating, brainstorming ideas for a small passive solar unit, then - using limited materials - adapt an existing box into a more efficient passive solar box. .... In short, the programming helped us objectively and quickly analyze our design process." 
Table 1: Breakdown of the number of student commenting on which projects integrated programming and design.

\begin{tabular}{|l|c|c|}
\hline & \multicolumn{2}{|c|}{ \# Students Commented } \\
\hline \multicolumn{1}{|c|}{ Project Mentioned } & $\begin{array}{c}\text { Robotics Themed } \\
\text { N=35 }\end{array}$ & $\begin{array}{c}\text { Sustainability Themed } \\
\text { N=31 }\end{array}$ \\
\hline Sumo 2 & 29 & \\
\hline Final Design Project & 6 & 5 \\
\hline Solar Water Heater & & 2 \\
\hline Arduino Thermostat & & 24 \\
\hline Passive Solar Boxes & & \\
\hline
\end{tabular}

\section{Question 2: Discuss how the projects in this course connect with real-world engineering problems. Numeric results are shown in Table 2.}

For this question, there was a large variety of responses for both cornerstone themes. There was a lot of focus as expected on the final design projects, either their own, or projects from other groups. Many students talked about using the design process as being a crucial part of the connections to real-world engineering and how they had accomplished that. There were 5 or so comments in each theme, that were more general in tone, stating that the course had connected them through the various projects and teamwork, they did not necessarily talk about one particular project. Many students mentioned more than one, as the data would indicate. This clearly shows the desired outcome of the students connecting the course projects to real-world engineering problems.

Table 2: Breakdown of the number of student commenting on how projects connected to real world problems.

\begin{tabular}{|l|c|c|}
\hline \multicolumn{1}{|c|}{ Project Mentioned } & $\begin{array}{c}\text { Robotics Themed } \\
\mathrm{N}=35\end{array}$ & $\begin{array}{c}\text { Sustainability Themed } \\
\text { N=31 }\end{array}$ \\
\hline Final Design Project & 23 & 16 \\
\hline Design Process & 21 & 15 \\
\hline Weekly labs/Integrated project & 11 & 13 \\
\hline Robotics field of study & 10 & \\
\hline Sumo robots & 10 & \\
\hline Final design projects of other groups & 8 & \\
\hline Reverse Engineering & 7 & \\
\hline Professional skills & 7 & \\
\hline Teaching STEM students & 5 & 6 \\
\hline Sustainability/ Sustainable Living & & 7 \\
\hline Energy Efficiency & & \\
\hline Team Work and Collaboration & & \\
\hline
\end{tabular}


Comments from Question 2:

"The projects in this course connect to real-world engineering problems because both incorporate the design process ... real problems being resolved by working engineers ... gives us a better understanding of how to go about working on these problems and similar ones in the future."

"All of these problems are prime examples of issues that face engineers. We were able to come up with viable solutions using the engineering design process."

"Each project really modeled something real engineers out there in the work force would be doing."

"The projects in this course connected with real world engineering problems in a variety of ways. The projects provided an active engagement in the process of engineering, ranging from design to analysis to implementation. By providing an interactive, yet structured, simulation of engineering situations, the projects allowed for the class to experience the trials and tribulations which typically faced those in the field of engineering, such as logistics, supply management, and optimization."

"The problems in this course are relevant to the real world, and important to the betterment of society at large. The focus of the course was sustainability, and the specific issues we examined-from water efficiency to renewable, off-the-grid energy and a home's carbon footprint, are all very real engineering issues outside of the class. In the real world, creating sustainable, off the grid houses happens all the time, and creating a practical working solar water heater as we did early in the course is a common design challenge faced by those looking to help third world peoples."

"There are many solutions that exist now or are close to becoming possible, but often implementing them is not as easy as it initially seems. As we found working on the minor design projects and semester design project in this class, there are often many complicated factors and challenges to look at when designing a sustainable future for our generation, and this is an issue in engineering through our generation."

\section{Question 3: Write a detailed problem statement from one of the engineering problems} discussed in question 2 above. Explain how one of your projects from the course applied to help solve that problem.

All students wrote reasonably good problem statements, this is the outcome we were looking for. Here are some examples of the problem statements that they wrote that reflect this:

"The company needs an autonomous vehicle capable of mapping the area surrounding Olympus Mons on Mars. It must be able to navigate the baod of the mountain using our satellite in stationary orbit as a guide. It must be able to navigate obstacles, as well as withstand Mars weather. It should last for a period of 5 years, while maintaining an average 
speed of 3 miles per hour. It can be no larger than 12 cubic meters in volume. The vehicle must take pictures of the area surrounding the mountain."

"Build a robot that can draw the blood of patients infected with deadly diseases while keeping the patient and doctor safe. The robot must be sanitary and uphold a medical quarantine."

"We must design and implement a plan for teaching children the engineering design process and the basics of robot design. Members of the Blank Boys and Girls Club should be educated thoroughly and efficiently to understand and utilize the engineering design process and to execute this process in the context of design and constructing robots using the Lego Mindstorms EV3 Kit. “

"Houses in America consume more water and energy, on average, than most other countries, yet do not produce any resources themselves. While homes are designed with better insulation and more energy and water efficient appliances, the fact remains that consumption is at an all time high, and growing. Homes need to be designed with both efficiency and selfsufficiency at the forefront of design if they are to be sustainable moving forward. Our designed homes seek to address this problem by creating houses that are both energy efficient and self-producing systems, as they are designed to survive completely off the grid, and thus able to produce their own utilities and use them efficiently as they are not abundant."

"The revised problem statement for our semester design project was "Design a home that is not dependent on outside sources for water or energy which uses recycled or environmental materials." One of the criteria highlighted in the problem statement is the self-sufficient energy use of the house. In order to be self-sufficient, the house would have to generate enough electricity to meet its demands, so it was important to try and limit the amount of electricity used. This is where the passive solar box minor design project became very useful. From this minor project, we learned how to effectively design a passive solar home, including window placement and the use of high thermal mass materials to retain heat overnight that we applied to our final project design."

"The problem statement for the issue of a solar hot water heater design for developing nations is as follows: Design an affordable, easily produced solar hot water heater that can quickly and safely heat to boiling an amount of water appropriate for an individual's hotwater needs using only the sun's energy."

Question 4: Explain how programming is needed in engineering problem solving. List examples from the course. (Numeric results are shown in Table 3.)

Two major themes emerged in this question. The first was the importance of data analysis in problem solving. There were many examples cited by the students about the problems having a real world engineering context, and that using data analysis and programming was used by engineers extensively. 
The other theme was that programming is used to control systems, machines and other functions. For the Robotics theme this was logically used to control robots. Which was seen as a representative skill, if programming controls robots, it can control many other key systems. For the Sustainability theme, the students cited the Arduino thermostat project where they made a control system that turned the heating element on and off depending on the temperature sensor input.

There were some other key areas mentioned, such as programming helped with algorithmic thinking which is integral to problem solving, and some students mentioned it was an essential skill for all engineers, not just one major.

Table 3: The number of student commenting on how programming is needed in engineering problem solving.

\begin{tabular}{|l|c|c|}
\hline \multicolumn{1}{|c|}{ Project Mentioned } & $\begin{array}{c}\text { Robotics Themed } \\
\mathrm{N}=35\end{array}$ & $\begin{array}{c}\text { Sustainability Themed } \\
\mathrm{N}=31\end{array}$ \\
\hline Data analysis & 25 & 30 \\
\hline Essential skill for engineers & 4 & 2 \\
\hline Algorithmic thinking & 6 & 1 \\
\hline Models real world & 1 & 19 \\
\hline $\begin{array}{l}\text { In the function of } \\
\text { systems/machines/robots }\end{array}$ & 23 & \\
\hline Arduino Thermostats & & \\
\hline
\end{tabular}

Additional quotes:

"Programming is essential in nearly every piece of equipment and in most engineered solutions. One would be hard pressed to find hardware without any software used in its implementation. “

"Programming is necessary in engineering problem solving in both a literal and metaphorical sense. [examples given of use of programming] ... There is also a certain level of programming knowledge that gets ingrained into the brains of engineers and changes the way they think..."

"Programming is a critical part of real world engineering problem solving that can be used for an incredibly wide range of applications. Engineers can use programs to perform long series or calculations and algorithms, autonomously control software and hardware systems, organize and graph data sets along with..."

"All we need are the critical thinking skills to know what we would want a machine or a system to do for us, and a program can complete this thought and turn it into an ideal situation" 
"Engineering and computer programming are becoming increasingly integrated, as we depend on technology to make our lives and daily tasks more efficient. Everything from energy efficiency to water efficiency to transportation efficiency and traffic control can be optimized by the use of programming."

"Programming is needed primarily to crunch data sets and get meaning out of long lists of numbers. This data processing was apparent in almost all of our design projects, in which we produced graphs and ran mathematical calculations on information gathered by sensors in each of the designs (solar water heater, passive solar box). Without programming, we would have no way of knowing how each of the designs performed, and thus what needed to be improved for the redesign. As a result, programming proved invaluable in sorting through data sets to assess results."

Some general comments about the course illustrate more completely that the course accomplished what had been intended, and the hands on, real world emphasis had resulted in combining the content threads and skills cohesively, yet maintained the content integrity.

"I personally found this semester in Robotics to have been one of the most productive and knowledgeable semesters in my schooling history. Learning multiple types of software, working hands-on with actual robots, and having the opportunity to teach middle school students, I am blessed to have been able to partake in such a useful course. Entering the class as a Mechanical Engineer, I was a little intimidated by the coding aspec, but was very excited about working with robots. I soon found out that this class properly integrated the two into a combination that truly peaked my interest and showed a new side of programming. Previously, I never saw a relationship between working as a Mechanical Engineer and being able to code, however, after this course I see the real importance of codes"

"Walking into Cornerstones of Engineering with absolutely no programming experience and walking out with both a familiarity and an appreciation for programming and its usefulness in design speaks to the integrity and effectiveness of the course. The integration of GE1110 and GE1111 into one course make learning both aspects of engineering more fun and easier to understand. Being able to learn at my own pace, on my own time through videos and homework assignments, while being able to work on hands-on activities in class and receiving one-on-one help when I needed it made learning new material much easier.'

"What is most important is that the steps that we took to design a home, as freshman college students with limited background in the field and realistic parameters to work within, are totally feasible in the real world. What we have done in a report is something that can be duplicated and engineered by companies today, which is very exciting and puts the problem into perspective."

Working from the positive comments and outcomes, and recognizing the challenges and drawbacks of the full cornerstone model, (one semester, 2 courses, 8 credits), in 2015 both full cornerstone and split cornerstone (Fall and Spring, each 4 credits, same cohort of students) were offered. 


\section{Discussion and Results for Full Cornerstone - 2015 (Year 2)}

In 2015, 4 sections of full cornerstone were offered in the same 8 credit format as the pilot again to students with qualifying AP credit status. The expected course outcomes remained unchanged and the project-based aspect and milestone style assignments were updated to reflect the new instructors' themes. The two themes of this iteration were Sustainability and Efficient Energy Production/Transfer Systems. The two sustainability sections had 61 students in total completed the course and the energy sections had a total of 60 students over two sections. The instructors of this iteration of cornerstone prepared the courses in the summer of 2015 while consulting the previous year's instructors for best practices and to ensure consistency between iterations. The main change between the pilot and year two, besides one of the themes, was the inclusion of more team evaluations and checks and balances of team work through the use of team contracts and CATME, an NSF funded web-based application that implements best practices in managing student teams.

The sustainability course utilized a new instructor but many of the same homework and lab assignments. The course was updated to reflect the comments from the previous year's students and the style of the instructor. Instead of doing a regimented sustainable home design project, students were given an open-ended project that asked them to design an educational museum exhibit that teaches its users about sustainability in either the area of energy or water. The openended approach was offered to allow the students coming from all 7 of the engineering majors a chance to develop a project that best fit their own interests. Instead of 3 large milestones, students were given 7 smaller milestones that continually built on one another and incorporated design and programming homework aspects from the original GE1110 (Engineering Design) and GE1111 (Engineering Problem Solving with Computation) courses. These milestones included: (1) Brainstorming and Design Selection, (2) Market Research and Preliminary Design Review, (3) Preliminary Prototyping and Hardware Component Demos, (4) Design Update and Preliminary Data Collection, (5) Gallery Walk: Design and Data Updates, (6) Peer Critique of 80\% Complete Written Reports and Gallery Walk of Updated Designs, and (7) Presentations to Faculty Judges and completed written report submission. Incorporated into each one of the milestones was a presentation aspect that was provided by a rotating project manager (for the first 4 milestones) giving a formal individual presentation, informal group presentations using gallery walk techniques (next two milestones), or formal group presentations of the final projects for the final milestone.

Similar exams and assignments were utilized from previous iterations by this instructor of GE1110 and GE1111 so as to be able to compare student performance. An analysis comparing final grades and major exams of previous students in the separate courses versus the current cornerstone grades showed no significant differences in performance. This seems to indicate that, again, despite the intensive load of the full cornerstone course student grades and overall performance were not negatively impacted. Anecdotally, final student projects in the full Cornerstone course were of higher quality and displayed more care and detail than past final design projects from the GE1110 from the same instructor. Faculty associated with 
sustainability research were invited to judge milestone 7 , where students gave a formal final group presentation of their work to each judge as the came by. Overall feedback indicated that the projects were ambitious, provided a decent base level of sustainability knowledge, and were impressive for the freshman level. The following quotes were reported by faculty on the final design project judging forms:

"The projects here today are on the same level [of difficulty] as the capstone projects 15 years ago."

"The wave pool project is something like what I do with my upperclassman. I am impressed that these are freshman projects."

"I loved the homemade maglev track! A really clever idea and exhibit. Some problems with execution, but that's understandable given the complexity of the exhibit."

"What a difficult product to model, but it works! Great interactivity!"

"I watched this project evolve and was impressed with the concept. I was also impressed with how ambitious they were. They couldn't always achieve their goals due to technical limitations, but they put forth good effort!"

In the Energy Production/Transfer Systems theme, student project teams were tasked to identify a system and design, draw, and build a prototype or design a simple model to demonstrate energy production and energy transfer and present it to public. This project was achieved using four major team activities were intergraded with the course work (1) Case Studies on Energy Systems, (2) Efficient Energy Transfer System Design, (3) Wind Fan Design and Analysis, and (4) Strong I-Arms Design and Measurements. The objective of the first activity for students was to explore and get the basic knowledge on the existing energy production and transfer system via literatures and/or field trip. The second activity was to help students to design and calculate energy loss and system efficiency, which is an important aspect of the course theme. The third was designed to aid students to gain basic knowledge in the wind turbine structure and design, which are common concepts in many wind/water based energy related designs. The fourth activity was to learn the fundamentals of designing strong structures to withstand high wind speed and earthquake. These concepts were expected to aid the final design project. Student's perception of the course and final project were captured in an exit survey from the course. Some quotes form the students included:

"[I really enjoyed] the integration of all elements we learned for the final design projects: from Matlab to SolidWorks."

"[I really enjoyed] the hands-on activities and experimentation." 
"[I really enjoyed] the integrated content of this course, the fact that we made things, and the final project."

Despite the high quality projects and full cornerstone students' ability to perform as well as in the traditional two course model, student responses to the full cornerstone were mixed in this second pilot run. Because split cornerstone modules were also running at the same time, students in full cornerstone lamented about their intense workload compared to their peers. The reality of this is true, they did have double the work to complete in the same amount of time outside of class, which may make full cornerstone prohibitive to students who are not used to high rigor such as the honors students and students with AP credits who are currently allowed in the course. While the workload was perceived as intense, it is most important to note that students' performance did not falter and learning outcomes were all met. At the conclusion of the course students said at a wrap up class that they felt proud of their ability to complete the difficult work and that they felt better prepared for tougher courses ahead. We will continue to make adjustments to the course in future iterations of full cornerstone but believe that the model works very well and produces top quality results in the type of students currently selected for full cornerstone. As students from the second full cornerstone pilot move into their spring and summer semesters, we will continue to monitor their progress and anticipate similar outcomes as students from the first pilot: accelerated trajectory in their courses taken and a more opportunities available to them in their first summer. Follow up data from full cornerstone students will be looked at in future research papers.

\section{5-2016 Cornerstone - New Approach}

Beginning in the fall of 2015, it was determined that it was not possible to only run the 8 credit cornerstone courses due to instructor loading and facilities issues. In addition, the heavy workload and shorter time frame is not ideal, both logistically and pedagogically. Due to the need, full cornerstone sections remained, with improvements learned from the pilot year. However a number of sections of "split" Cornerstone have been added and piloted. This is an 8credit, 2-semester version with the same content except now carried across 28 weeks of 195 minutes per week of instruction. An initial review of these new sections has already yielded some interesting trends. First, students benefit from additional out-of-class time to spend on the projects and homework. Having 400 minutes of instruction per week in the full cornerstone is a very difficult load even for the best students due to the increased pace and halving of the number of weekends to absorb the material. The split cornerstone covering the same material across two semesters allows for more "gel" time. Second, combining design with topics like programming can be difficult to grasp quickly. Slowing the pace and spreading the instruction over two semesters provides additional time to better integrate the topics into smaller design-and-build projects first, allowing students to see real world applications and gain the necessary skills before applying them to an end of the term project. Third, it allows the faculty to revisit in the spring semester some of the topics that were first introduced in the fall semester as students continue to apply those subjects in the spring semester design projects. Finally, the split cornerstone helps to 
even the first-year engineering faculty workload across the fall and spring semesters and makes it possible to schedule all of the necessary computer classroom time in the college's labs.

A few additional faculty are piloting the split cornerstone approach this year. Based on instructor interest and expertise, three new themes were introduced to these sections. The themes are meant to represent content areas that cut across multiple engineering disciplines and that have environmental, exploratory, or artistic concerns with broad appeal. This year, split cornerstone themes included robotics, security, and game design, and additional themes being explored for the future include music and bio-engineering. As with the full cornerstone, students' assignments and projects tie desired learning objectives to real applications within each section's theme. Some examples of the themes' design projects this year are: (robotics) an autonomous Sumo robot competition, (security) an Arduino-based system to detect counterfeit goods using a variety of student-selected sensors, and (games) a mini-golf hole that is both playable and instructive to a physics or mathematics topic of the students' choice through the use of embedded electronics and sensors.

Among the challenges of adopting the 14-week course to the 28-week course was in deciding which topics would be taught during the first semester and which during the second semester. For this pilot, it was decided that the first semester would focus on the more foundational aspects of nearly all of the desired content areas, while the second semester would complete the instruction in each area using the context of a longer duration, team-based, engineering design project. As an example, programming was split according to first semester: $\mathrm{C}++$ basics, variables, loops, and branching; and second semester: $\mathrm{C}++$ functions, arrays, and file $\mathrm{I} / \mathrm{O}$, and all topics in MATLAB. Preliminary student feedback after the first semester has been very positive, and additional assessment is planned at the completion of the first split cornerstone courses in spring 2016.

\section{Cornerstone Courses - The Future Curriculum and Plan}

The future curriculum for first-year engineering students will include both Full Cornerstone (Integrated 8-Credit course in one semester) and Split Cornerstone (Integrated 4-credit course in two semesters). After two complete iterations of full Cornerstone, we believe that stable grade distributions on projects and exams indicate that this model of integrated design experience in the first-year provides equal measured learning outcomes to our separate course model for our most competitive students (both honors and those entering with AP credits.) We believe the intense course load intellectually challenges our most competitive students and we see that it enables them to pursue classes in their intended major earlier (spring of first-year) due to the completion of their first year engineering requirements in the fall semester. This early start on their education allows our competitive students to explore their opportunities for research, job experiences, and advanced degrees after the first-year, providing an accelerated model for our increasingly competitive student population. We will continue to collect data on student performance in full Cornerstone and optimize this model for our competitive student population in future years. 
This year was the first year we offered split cornerstone to our traditional student population (non-honors and those without AP credit) so this is ongoing and considered a pilot, although it includes many more students. We will be collecting data at the completion of the second semester to confirm the results we have seen in full Cornerstone: that there are no adverse effects on learning outcomes (as indicated by grades analysis) and students are provided a richer learning environment through our new integrated approach to first-year engineering. Data will be forthcoming in future papers.

Overall, it is hard in a paper to convey the positive outcomes seen by all of the instructors involved and following discussions with students from Fall 2014 and 2015, from both Full and Split Cornerstone sections. Many students in Fall 2014 came back to report that they had been able to take sophomore level courses such as "Enabling Robotics" in the Spring of their first-year and were able to find competitive REU's and co-op jobs as a result of the accelerated pace of their coursework. The students are excited about their projects; they are much invested in their success and overcoming the numerous challenges and problems. The increased level of activity in the first-year project space is well documented with lab hours needing to be extended, more lab supervisors hired and more 3D printers purchased. A steady level of semi-chaotic project testing, constructing and seeking help persisted throughout the semester. Previously in the two course sequence the major projects were design on paper for the most part. Now the projects are large-scale, working prototypes, like the autonomous robots, sustainable home mockups, and energy-efficient systems that integrate design, evaluation, critical thinking, programming, communication, graphics, and real world problems. So what started as a means to help one cohort of students with advanced AP credits get exposure to their major sooner has now benefited the rest of the first-year population. One final challenge is that not all students are in a cornerstone section and do have a perception that they are missing something. For the Fall 2016 semester our goal is to have all incoming first-year students in a cornerstone section.

Bibliography

1. Allam, Y. S., Whitfield, C. A., \& Phanthanousy, J. N. (2012). Scaffolding provided to engineering students in cornerstone design project scenarios related to practices of expert designers. American Society for Engineering Education Conference Proceedings, San Antonio, TX, Paper ID \# 3920.

2. Donahue, S. K. (2012). The impact of a hybrid instructional design in a first-year design cornerstone course on student understanding of the engineering design process. American Society for Engineering Education Annual Conference Proceedings, San Antonio, TX, Paper ID \#3555.

3. Doyle, T. (2009). Cornerstone design: Product dissection in a common first-year engineering design and graphics course. American Society for Engineering Education Annual Conference Proceedings, Austin, TX, Paper ID \#2068.

4. Dym, C. L., Gilkeson, M. M., \& Phillips, J. (2012). Engineering design at Harvey Mudd College: Innovation institutionalized, lessons learned. Journal of Mechanical Design, 134(8) doi:10.1115/1.4006890 
5. Elzey, D. (2006). Teaching intro to engineering in context - UVA engineering's new cornerstone. American Society for Engineering Education Annual Conference, Chicago, IL, Paper ID \#1574.

6. Haungs, M., Clements, J., \& Janzen, D. (2008). Improving engineering education through creativity, collaboration and context in a first year course. American Society for Engineering Education Annual Conference, Pittsburgh, PA, Paper ID \#464.

7. Khalaf, K., Balawi, S., Hitt, G. W., \& Radaideh, A. (2012). Freshman engineering design: A new model content and pedagogy. IEEE Global Engineering Education Conference, 1-6. doi:10.1109/EDUCON.2012.6201101

8. Rahmat, R. A. A. O. K., Yatim, M. Y. M., Maulud, K. N. A., Yusoff, N. I. M., \& Mutalib, A. A. (2012). The effectiveness of basic design project (cornerstone) in students' competency development. Procedia - Social and Behavioral Sciences, 60, 56-60. doi:10.1016/j.sbspro.2012.09.346

9. Walton, S. P., Briedis, D., Urban-Lurain, M., Hinds, T., \& Davis-King, C. (2013). Building the whole engineer: An integrated academic and co-curricular first-year experience. American Society for Engineering Education Annual Conference, Atlanta, GA, Paper ID \#7410.

10. Williams, C., Crede, E., Terpenny, J., \& Goff, R. (2010). Effects of student-customer interaction in a cornerstone design project. American Society for Engineering Education Annual Conference, Louisville, KY, Paper ID \#2201.

11. Brannan, K. P., \& Wankat, P. C. (2005). Survey of first-year programs. American Society for Engineering Education Annual Conference, Portland, OR, Paper ID \#855.

12. Todd, R. H., \& Magleby, S. P. (2004). Evaluation and rewards for faculty involved in engineering design education. International Journal of Engineering Education, 20(3), 333.

13. National Academy of Engineering. (2005). Educating the engineer of 2020: Adapting engineering education to the new century. Washington, D.C.: National Academies Press.

14. Emami, M. R. (2009). Application of learning models to the engineering design pedagogy. American Society for Engineering Education Annual Conference, Austin, TX, Paper ID \#1370.

15. Hirsch, P., Shwom, B., Yarnoff, C., Anderson, J., Kelso, D. M., Olson, G. B., \& Colgate, J. (2001). Engineering design and communication: The case for interdisciplinary collaboration. International Journal of Engineering Education, 17(4-5), 342-348.

16. Grimheden, M. (2007). From capstone courses to cornerstone projects: Transferring experiences from design engineering final year students to first year students. American Society for Engineering Education Annиal Conference Proceedings, Honolulu, HI, Paper ID \#1582.

17. Malik, Qaiser Hameed. (2010). Measurement of student attitudes in first year engineering - a mixed methods approach (Doctoral dissertation). Retrieved from ProQuest. (898326507; ED523123).

18. Dym, C. L., Agogino, A. M., Eris, O., Frey, D. D., \& Leifer, L. J. (2005). Engineering design thinking, teaching, and learning. Journal of Engineering Education, 94(1), 103-120.

19. Quinn, D., Smith, E. J., \& Mahfuzul Aziz, S. (2011). First year engineering learning space enhancing the student experience. American Society for Engineering Education National Conference, Vancouver, British Columbia, Canada, Paper ID \#1311. 
20. Wilczynski, V., O'Hern, C. S., \& Dufresne, E. R. (2014). Using an engineering design center to infuse design experience into a mechanical engineering program. American Society for Engineering Education, Indianapolis, IN, Paper ID \#9822.

21. Hinds, T., Wolff, T., Buch, N., Idema, A., \& Helman, C. (2009). Integrating a first-year engineering program with a living-learning community. American Society for Engineering Education Annual Conference, Austin, TX, Paper ID \#1922.

22. Hinds, T., Wolff, T., Buch, N., Idema, A., \& Davis-King, C. (2010). First-year engineering: A comprehensive approach. American Society for Engineering Education Annual Conference, Louisville, KY, Paper ID \#1502.

23. Freeman, S. F., Jaeger, B. K., \& Brougham, J. C. (2003). Pair programming: More learning and less anxiety in a first programming course. American Society for Engineering Education Annual Conference, Nashville, TN., Paper ID \#359.

24. Whalen, R., Freeman, S. F., Jaeger, B. K., \& Maheswaran, B. (2005). Teamwork is academic: The gateway approach to teaching engineering freshmen. American Society for Engineering Education Annual Conference, Portland, OR, Paper ID \#103.

25. Freeman, S., Jaeger, B. K., \& Whalen, R. (2006). Active teaching, active learning: Infusing the design process into a first-year course. American Society for Engineering Education Annual Conference, Chicago, IL, Paper ID \#1001.

26. Jaeger, B. K., \& Bilen, S. (2006). The one-minute engineer: Getting design class out of the starting blocks. American Society for Engineering Education Annual Conference, Chicago, IL, Paper ID \#911.

27. Jaeger, B. K., Bates, M., Damon, B., \& Reppy, A. (2008). Tipping the scales: Finding the most effective balance between lecture versus active learning across academic levels in engineering. American Society for Engineering Education Annual Conference, Pittsburgh, PA, Paper ID \#2574.

28. Whalen, R., Freeman, S. F., \& Jaeger, B. K. (2008). Agile education: What we thought we knew about our classes, what we learned, and what we did about it. American Society for Engineering Education Annual Conference, Pittsburgh, PA, Paper ID \#1647.

29. Jaeger, B. K., Freeman, S. F., Whalen, R., \& Payne, R. (2010). Successful students: Smart or tough? American Society for Engineering Education Annual Conference, Louisville, KY, Paper ID \#1033.

30. Whalen, R., Jaeger, B. K., \& Freeman, S. F. (2011). R U all there? texting, surfing, and e-tasking in the classroom and its effects on learning. American Society for Engineering Education Annual Conference, Vancouver, British Columbia, Canada, Paper ID \#537.

31. Jaeger, B. K., Freeman, S. F., \& Whalen, R. (2012). Programming is invisible or is it - how to bring a first-year programming course to life. American Society for Engineering Education, San Antonio, TX, Paper ID \#4011.

32. Freeman, S. F., Jaeger, B. K., \& Whalen, R. (2014). Making a first-year impression: Engineering projects that affect and connect. American Society for Engineering Education Annual Conference, Indianapolis, IN, Paper ID \#9599. 